\title{
Kan Donörlerinde HBsAg, Anti-HCV, Anti-HIV ve Sifiliz Seroprevalansı
}

\author{
Seroprevalence of HBsAg, Anti-HCV, Anti-HIV and Syphilis in Blood Donors
}

Mehmet PARLAK ${ }^{1}$, Suat ÖZLÜK ${ }^{1}$, Cengiz DEMİR ${ }^{2}$, Cennet RAĞBETLí1

${ }^{l}$ Yüzüncü Yll Üniversitesi Tip Fakültesi Tibbi Mikrobiyoloji Anabilim Dall, VAN

${ }^{2}$ Yüzüncü Yıl Üniversitesi Tıp Fakültesi İç Hastalıkları Anabilim Dalı, VAN

\begin{abstract}
ÖZET
Kan transfüzyonuyla bulaşabilen Hepatit B virusu (HBV), Hepatit $\mathrm{C}$ virüsü (HCV), İnsan immun yetmezlik virusu (HIV) ve Sifiliz kan merkezi donörlerinde zorunlu olarak taranmaktadır. Bu çalışmada, kan bağışı için merkezimize başvuran kişilerde $\mathrm{HBsAg}$, anti-HCV, anti-HIV ve sifiliz test sonuçlarının seroprevalansını değerlendirilmesi amaçlanmıştır.

Ocak 2010-Mart 2015 tarihleri arasında Yüzüncü Yıl Üniversitesi Dursun Odabaş Tip Merkezi Kan Merkezine başvuran toplam 27365 kan bağışçısının tarama testi sonuçları retrospektif olarak incelenmiştir. $\mathrm{HBsAg}$, anti-HCV, anti-HIV ve sifiliz testleri Architect i1000SR (Abbott Diagnostics, Almanya) cihazı kullanılarak kemilüminesan ELİSA yöntem ile çalışılmıştır.

Toplam 27365 kan bağışçısının 26077'ünün $(\% 95,2)$ cinsiyeti erkek, 1288'sinin $(\% 4,8)$ cinsiyeti ise kadındı. HbsAg 112 $(\% 0,4)$, anti-HCV $15(\% 0.05)$, sifiliz $32(0.12)$ ve 6 donörde HIV pozitifliği tespit edildi. Anti-HIV pozitif saptanan 6 kişinin kanı doğrulama testi ile negatif olduğu tespit edilmiştir.

Tarama testleri için bulunan seropozitiflik değerleri diğer çalışmalara göre düşük olarak tespit edilmiştir.
\end{abstract}

Anahtar Kelimeler: Kan donörleri, HBsAg, Anti-HCV, AntiHIV, Sifiliz

\section{GİRIȘ}

Tek kaynağ1 insan olan kan ve kan ürünlerinin transfüzyonu, yaşam kurtarıcı ve destekleyici olarak hastanelerde yaygın olarak kullanılmaktadır. Transfüzyon esnasında kan veya kan ürünlerinin yanında enfeksiyon etkenleri de alıcıya geçebilmektedir. Alıcıya geçen enfeksiyon etkenlerinin çoğu, kanda günlerce canlı olarak bulunabilmekte ve alıcıda daha kalıcı sorunlara neden olabilmektedir.

\section{ABSTRACT}

Transfusion-transmitted Hepatitis B virus (HBV), Hepatitis C virus (HCV), Human immun deficiency virus (HIV) and Syphilis are obligatory for screening in blood bank donors. In this study, we purposed to evaluate the seroprevalance of $\mathrm{HBsAg}$, anti-HCV, antiHIV and syphilis the serologic screening results in blood donors who applied to transfusion center.

Screening tests results of a total of 27365 blood donors, which have been admitted the Yuzuncu Y1l University Dursun Odabas Medikal Center Blood Center for blood donation between January 2010 and March 2004, evaluated retrospectively. HBsAg, anti HCV, anti HIV and syphilis tests were performed on the blood of donors by the chemiluminescense ELISA method (Architect i1000SR, Abbott Diagnostics, Germany).

A total of $26077(95,2 \%)$ of 27365 blood donors were male and $1288(4,8 \%)$ were female. HBsAg was positive in $112(0,4 \%)$, anti$\mathrm{HCV}$ in $15(0.05 \%)$, syphilis in $32(0.12)$ and anti-HIV in 6(0.02\%) of the donors. Confirmation test was reported negative the 6 antiHIV positive donors.

The seropositivity rates for screening test results were found lower according to the other studies.

Keywords: Blood donors, HBsAg, Anti-HCV, Anti-HIV, Syphilis Dolayısıyla, kanın uygun şekilde elde edilerek uygulanması önem arz etmektedir $(1,2)$.

Hepatit B, Hepatit C, Human İmmunodeficiency Virus (HIV) ve Sifiliz kan transfüzyonu ile geçiş riski taşıyan majör patojenlerdir. Tüm dünyada yaklaşık 2 milyardan fazla kişinin Hepatit B virüsü (HBV) ile temas etmiş olduğu, 400 milyon kişinin $\mathrm{HBV}$ ile enfekte olduğu bilinmektedir. Her yıl yaklaşık bir 
milyon kişi HBV ile ilişkili siroz ve hepatoselüler karsinom gibi nedenlerle hayatını kaybetmektedir (3). Hepatit C virüsü (HCV) açısından ise dünyada yaklaşık 170 milyon kişinin enfekte olduğu düşünülmektedir. Türkiye'de genel popülasyonda Anti-HCV pozitifliğinin yaklaşık \%0,6 olduğu kabul edilmektedir. HCV'nin henüz tanımlanmadığı yıllarda posttransfüzyon hepatit oranının \%10'a vardığ bilinmektedir (4).

Kan naklinin güvenli bir şekilde gerçekleşmesi için, Dünya Sağlık Örgütü (DSÖ) kan transfüzyonu ile geçebilen sözü geçen patojenlerin, güvenirliliği ve kalitesi kanıtlanmış testlerle araştırılması, uyumlu çalışan bir kan transfüzyon servisinin kurulması ve etkili kalite kontrol sistemlerinin uygulanması önerisinde bulunmaktadır (5). Çalışmada hastanemizde kan donörlerinde taranması zorunlu olan, transfüzyonla bulaşan enfeksiyon etkenlerinin görülme sıklığının belirlenmesi amaçlanmıştır.

\section{GEREÇ VE YÖNTEM}

Çalışmada Ocak 2010-Mart 2015 tarihleri arasındaki beş yıllık dönemde Yüzüncü Yıl Üniversitesi Tıp Fakültesi Dursun Odabaş Tıp Merkezi Kan Merkezi'nde donör sorgulama formu doldurup kan vericisi olarak uygun görülen 18-65 yaşları arasındaki kişilerde HBsAg, anti-HCV, anti-HIV 1/2 ve sifiliz test sonuçları retrospektif olarak değerlendirilmiştir. Kan Merkezinde HBsAg, anti-HCV, anti-HIV 1-2 ve sifiliz testleri kemilüminesan yöntemle (Architect i1000SR, Abbott Diagnostics, Almanya) araştırılmıştır. HBsAg, anti- HCV ve anti-HIV için $\geq 1 \mathrm{~S} / \mathrm{CO}$ bulunan örnekler reaktif olarak değerlendirilmiştir. HBsAg ve anti-HCV için 1-10 S/CO bulunan örnekler ve anti-HIV pozitif saptanan tüm örnekler tekrar edilmiştir. HBsAg, antiHCV ve anti-HIV 1-2'de pozitif çıkan örnekler kayıt altına alınarak imha işlemi uygulanmıştır. Anti HIV testinde ikinci kez pozitif çıkan şahıslar doğrulama ve takip amacı ile enfeksiyon hastalıkları bölümüne yönlendirilmiştir. Elde edilen veriler "Minitab v14" programına girilerek istatistiksel analizlerde $\mathrm{Z}$ testi ile oran karşılaştırması yapılarak p değerinin anlamlılık sınırı 0.05 olarak kabul edilmiştir.

\section{BULGULAR}

Çalışma süresince hastanemiz kan merkezine kan bağışçısı olarak 27365 kişi 32547 defa başvurmuştur. Kan donörü olarak başvuranların cinsiyetlerine baktığımızda 26077'si $(\% 95,2)$ erkek 1288'inin $(\% 4,8)$ kadın olduğu tespit edilmiştir. Kan donörlerinin toplamında $112(\% 0,4) \quad \mathrm{HbsAg}$ testi pozitifliği saptanırken, $15(\% 0,6)$ donörde Anti-HCV testi pozitifliği saptanmıştır. Sifiliz testi pozitifliği tespit edilenler $32(\% 1,2)$ kişi iken, anti-HIV testi pozitifliği tespit edilen $6(\% 0,2)$ kişinin kanı doğrulama testi ile negatif olarak tespit edilmiştir. HbsAg testi açısından 2012, 2013 ve 2014 y1llarında tespit edilen pozitiflik oranı 2010 ve 2011 yıllarına göre istatistik olarak anlamlı bulunmuştur. Yıllara göre kan donörlerinin sayıs ve pozitif saptanan $\mathrm{HBsAg}$, anti-HCV, antiHIV(1-2) ve sifiliz testi sayısı tabloda verilmiştir (Tablo 1).

Yaş dağılımlarına göre HBsAg pozitiflik oranları karşılaştırıldığında $18-25$ ve 46-55 yaşları ile 26-35 ve 46-55 yaşları arasında saptanan fark istatistik olarak anlamlı bulunmuştur. Anti-HCV, anti-HIV 1,2 ve sifiliz testi açısından ise yaşlar arasında istatistik olarak anlamlı fark saptanmamıştır (Tablo 2). 
Tablo 1. Yıllara göre pozitif saptanan HBsAg, anti-HCV, anti-HIV ve sifiliz sayıları

\begin{tabular}{lccccc}
\hline Yıllar & Donör Sayısı & HBV & HCV & HIV & Sifiliz \\
\hline 2010 & 3.468 & $7(0.2)$ & $1(0.03)$ & $1(0.03)$ & $0(0)$ \\
2011 & 5.268 & $5(0.09)$ & $2(0.04)$ & $0(0)$ & $2(0.04)$ \\
2012 & 3.134 & $17(0.54)$ & $0(0)$ & $2(0.06)$ & $2(0.06)$ \\
2013 & 6.672 & $40(0.6)$ & $5(0.07)$ & $2(0.03)$ & $9(0.13)$ \\
2014 & 7.497 & $39(0.52)$ & $4(0.05)$ & $1(0.01)$ & $16(0.21)$ \\
2015 & 1.326 & $4(0.3)$ & $3(0.23)$ & $0(0)$ & $3(0.23)$ \\
\hline Toplam & $\mathbf{2 7 . 3 6 5}$ & $\mathbf{1 1 2 ( 0 . 4 1 )}$ & $\mathbf{1 5 ( 0 . 0 6 )}$ & $\mathbf{6 ( 0 . 0 2 )}$ & $\mathbf{3 2}(\mathbf{0 . 1 2})$ \\
\hline
\end{tabular}

Tablo 2. Kan donörlerinde yaş dağılımlarına göre HBsAg, Anti-HCV, Anti-HIV ve Sifiliz test sonuçları

\begin{tabular}{lccccc}
\hline Yaş Grubu & Kan Bağış̧ısı & HBsAg & Anti-HCV & Anti-HIV & Sifiliz \\
\hline $18-25$ & 5325 & 18 & 3 & 0 & 5 \\
$26-35$ & 12474 & 45 & 6 & 6 & 17 \\
$36-45$ & 7083 & 30 & 5 & 0 & 5 \\
$46-55$ & 2157 & 17 & 1 & 0 & 4 \\
$56-65$ & 326 & 2 & 0 & 0 & 1 \\
\hline Toplam & $\mathbf{2 7 3 6 5}$ & $\mathbf{1 1 2}$ & $\mathbf{1 5}$ & $\mathbf{6}$ & $\mathbf{3 2}$ \\
\hline
\end{tabular}

\section{TARTIȘMA}

Kan transfüzyonunun tedavi amaçlı olarak kullanılmaya başlanmasından sonraki yıllarda alıcılarda transfüzyona bağlı olarak gelişen enfeksiyonlara karşı önleyici tedbirler alınmaya başlanmıştır. DSÖ, bağışçılardan temin edilen ve hastaya verilecek olan kanın güvenliği açısından " Verildiği kişide herhangi bir tehlike ya da hastalık oluşturmayan, enfeksiyon etkenlerini veya zararlı yabancı maddeleri içermeyen kan" tanımını yapmıştır (6). Güvenli kan temini için ülkemiz kan bankalarında rutin olarak $\mathrm{HBsAg}$, anti-HCV, anti-HIV ve Sifilize yönelik tarama çalışmaları yapılmaktadır.

Kan ve vücut sıvıları ile bulaşan HBV'nin kan donörlerinde rutin taranması ile transfüzyonla bulaşmada belirgin azalma olduğu belirtilmektedir
$(7,8)$. Şanlı ve ark (9) 2003-2012 yılları arasındaki on y1llık dönemde kan merkezine başvuran 51120 donörde yaptıkları çalışmada \%2,03 oranında HBsAg testi pozitifliği olduğunu ve süreç içerisinde $\mathrm{HBsAg}$ pozitiflik oranının azaldığını bildirmişlerdir. Konya ilinde yapılan bir çalışmada, 2003-2006 yılların arasında kan bağışçılarında HBsAg testi pozitiflik oranı $\% 1.75$ iken, 2006-2009 yılları arasında bu oran \%1.31 olduğunu ve HBsAg testi pozitifliğinde azalmanın istatiksel olarak anlamlı olduğunu tespit etmişlerdir (10). Kader ve ark (11) çalışmalarında kan merkezine başvuran 16362 donörde 2005 yılında HBsAg testi pozitiflik oranının \%0.79 iken, 2009 yılında bu oranın \%0.37’ye gerilediğini bildirmişlerdir. Ülkemizde yapılan başka bir çalışmada yedi yıllık dönemde kan bağışında bulunan 19499 kişide \%2.06 oranında 
HBsAg testi pozitifliği saptandığı ve yıllara göre HBsAg testi pozitifliğinin giderek azaldığı saptanmıştır (12). Dilek ve ark (13) 1995-2003 tarihleri arasında ilimizde daha önce kan donörlerinde HBsAg pozitifliğini $\% 2,1$ olarak bildirmişlerdir. Bizim çalışmamızda HBsAg testi pozitifliği toplam olarak $\% 0,4$ olarak diğer çalışmalardan daha düşük olarak tespit edilmiştir. 2010 ve 2011 yılları ile kıyaslandığında 2012-2014 yılları arasında HBsAg testi pozitifliğinin arttığı belirlenmiş ve 2015 yılında azalma saptanmıştır. Ancak ilimizde daha önce yapılmış çalışma ile kıyaslandığında pozitiflik oranının giderek azaldığı belirlenmiştir. Çalışma sonuçlarına göre HBsAg testi pozitifliğinin yıllara göre gittikçe azalmasının kan merkezlerinde donör sorgulama formunun etkin kullanılması, halkın HBV enfeksiyonuna karşı artan duyarlılığı, tetkik imkânlarının artmasıyla insanların kan bağışçısı olmadan önce tanı alması ve aşı uygulamaları ile sağlandığını düşünmekteyiz.

Kronik karaciğer hastalığı, siroz ve hepatoselüler karsinomaya yol açabilen HCV'nin bu hastalıklardaki rolü giderek artmaktadır. Transfüzyona bağlı HCV enfeksiyonu önceleri bütün dünyada önemli bir sorun halindeyken Anti-HCV testini kan bankalarında rutin tarama testine koyan ülkelerde yok denecek seviyeye düşmüştür. Ülkemizde de kan bağışçılarında Anti-HCV taranması 1996 yılında zorunlu tutulmuştur (14). Yakut ve ark (15) yaptıkları çalışmada 2000-2009 yılları arasında kan donörlerinde Anti-HCV testi pozitifliğinin \%0.59 oranında olduğunu; Erzurum'da Çelebi ve ark (16) yaptıkları araştırmada on iki yıllık dönemde kan bağışında bulunanlarda \%0.92 oranında Anti-HCV testi pozitifliğini olduğunu bildirmişlerdir. Güneydoğu Anadolu Bölgesi illerinden biri olan Batman'da yapılan üç yıllık bir çalışmada (17) Anti-HCV testi pozitifliği $\% 0,1$ olarak tespit edilmiştir. Turan ve ark (10) kan bağışçılarında \%0,5 oranında Anti-HCV testi pozitifliği olduğunu belirtmişlerdir. Çalışmamızda Anti-HCV testi pozitifliği \%0.06 oranında tespit edilmiştir. Diğer çalışmalara göre araştırmamızda Anti-HCV pozitiflik oranının düşük olduğu görülmektedir.

Kazanılmış immun yetmezlik sendromunun (AIDS) ilk olarak 1981'de ayrı bir hastalık olduğu tanımlanmıştır. O zamandan beri, AIDS, dünyada önemli toplum sağlığı sorunlarından birisi olmuştur. HIV, AIDS'e neden olan etken olup, dünyada HIV ile enfekte 42 milyondan fazla insan olduğu tahmin edilmektedir. Enfeksiyon Afrika ve Asya ülkelerinde yayılmaya devam etmektedir ve bazı Afrika ülkelerinde nüfusun \%30’u HIV ile enfektedir $(18,19)$. Ülkemiz HIV enfeksiyonu açısından düşük riskli ülkelerden olup, yapılan çalışmalarda kan donörlerinde Anti-HIV testi pozitiflik oranı Erzurum, Ankara, İzmir ve Isparta'da sirasiyla $\% 1.06, \quad \% \quad 2,2, \quad \% \quad 0.028, \quad \% 0,44$ tespit edilmiştir (16,20-22). Kırıkkale ve Batman'da ise antiHIV testi pozitif donöre rastlanmadığı bildirilmiştir $(17,23)$. Yapılan birçok çalışmada anti-HIV testi pozitif çıkan kan bağışçılarında doğrulama testilerinin negatif olduğu belirtilmiştir $(9,15,20,22,24)$. Buna karşın doğrulama testleri pozitif olarak belirlenen çalışmalar literatürde yer almaktadır $(11,12,16,21,25)$. $\mathrm{Bu}$ çalışmada da benzer şekilde altı donörde pozitiflik saptanırken bunların hiçbirisi doğrulanmamıştır. Ülkemizde HIV enfeksiyonunun düşük oranda görülmesinin sosyal ve kültürel yaşam ile ilgili olduğunu düşünmekteyiz.

İnsanlara özgü bir hastalık olan sifiliz, özellikle cinsel ilişki ile bulaşmaktadır. Modern tarama prosedürleri ile bu hastalığın kan transfüzyonu ile bulaşması hemen hemen elimine edilmiştir (7). Ülkemizde kan merkezlerinde yapılan çalışmalarda sifiliz testi pozitifliği \%0.02-2,3 oranları arasında bildirilmektedir $(9,11,12,15,16,22,24,25)$. Çalışmalara benzer şekilde kan merkezimize başvuran kan bağışçılarında sifiliz testi pozitiflik oran $1 \% 0.12$ oranında tespit edilmiştir. Hastaların yaşamları kan transfüzyonuyla kurtulurken, transfüzyondan kaynaklanan enfeksiyonlar kan alıcısı olan hastalarda daha kalıcı problemlere yol açabilmektedir. Kan nakli ile enfeksiyonların bulaşma 
riski, tarama testleri ile büyük oranda engellenmiş olmasına rağmen, risk devam etmektedir. Transfüzyondan kaynaklanan bulaş riski bölgesel yaygınlığının bilinmesi, kan merkezlerinde donör sorgulama formunun etkin kullanımı, şu anda etkin aşısı olan HBV için aşılama programları ve toplumu bilinçlendirme çalışmaları ile azaltılabilir. Hekimlerin de gereksiz kan ve kan ürünü transfüzyonundan kaçınması gerekmektedir.

\section{KAYNAKLAR}

1. Kaya S, Aridoğan BC, Adiloğlu AK, Demirci M. Isparta bölgesi kan donörlerinde HBsAg ve antiHCV seroprevalansı. SDÜ Tip Fak Derg. 2005: 12; 36-8.

2. Uluhan R. Güvenli kan. ANKEM Derg. 2007; 21: 142-5.

3. Özacar T. Hepatit B virüsü. In: Topçu-Willke A, Söyletir G, Doğanay M. Enfeksiyon Hastalıkları ve Mikrobiyolojisi. 3. Baskı. İstanbul, Nobel Tip Kitapevleri. 2008: 1882-904.

4. Akhan S. Hepatit C Virusu. In: Topçu-Willke A, Söyletir G, Doğanay M. Enfeksiyon Hastalıkları ve Mikrobiyolojisi. 3. Baskı. İstanbul, Nobel Tıp Kitapevleri. 2008: 1911-29.

5. Stokx J, Gillet P, De Weggheleire A, Casas EC, Maendaenda R, Beulane AJ, Jani IV, Kidane S, Mosse CD, Jacobs J, Bottieau E. Seroprevalence of transfusion-transmissible infections and evaluation of the pre-donation screening performance at the Provincial Hospital of Tete, Mozambique. BMC Infect Dis. 2011; 11:141. doi: 10.1186/1471-233411-141.

6. World Health Organization. Blood Transfusion Safety Team of the Department of Blood Safety and Clinical Technology 1-6, WHO Geneva. 2001.

7. Ryan KJ, Ray CG. Sherris Medical Microbiology. 6th edition. United States of America: McGrawHill Education, 2014.
8. Bienz KA. Hepadnaviruses: Hepatitis B Virus and Hepatitis D Virus. In: Kayser FH, Bienz KA, Eckert J, Zinkernagel RM. Medical Microbiology. 1st edition. Stuttgart: Thieme, 2005: 429-34.

9. Şanlı K, Sarı NG, Hatipoğlu N. Kan merkezimize başvuran donörlerin 10 yıllık tarama sonuçlarının değerlendirilmesi. JOPP Derg. 2013; 5: 136-41.

10. Turan H, Şerefhanoğlu K, Kanat Ünler G, Arslan H. Konya İlinde Kan Donörlerinde HBsAg ve AntiHCV seroprevalansı ve yaş ve cinsiyetle ilişkisi. Klimik Derg. 2011; 24: 36-9.

11. Kader Ç, Erbay A, Birengel S, Gürbüz M. Kan donörlerinde Hepatit B virusu, Hepatit C virusu, İnsan İmmün Yetmezlik virusu infeksiyonu ve Sifilis seroprevalansı. Klimik Derg. 2010; 23: 95-9.

12. Uzun C. Kan donörlerinde HbsAg, anti-HCV, antiHIV ve RPR sonuçlarının değerlendirilmesi. Türk Mikrobiyol Cem Derg. 2008; 38: 143-6.

13. Dilek İ, Demir C, Bay A, Akdeniz H, Öner AF. Türkiye'nin doğu bölgesindeki kan donörlerinde HBsAg, anti-HCV, anti-HIV ve VDRL seropozitivite oranlar1. Turk J Hematol. 2007; 24: 4-7.

14. Barut HŞ, Günal Ö. Dünyada ve ülkemizde Hepatit C epidemiyolojisi. Klimik Derg. 2009; 22: 38-43.

15. Yakut U, Güney M, Doğanay ÜD, Koçak A, Avcı IYY. Bir kan merkezinde bağışçılara uygulanan mikrobiyolojik tarama testleri sonuçlarının on yıllık değerlendirilmesi. Türk Mikrobiyol Cem Derg. 2010; 40: 201-6.

16. Çelebi D, Çelebi Ö, Altoparlak Ü, Kök AZ. Kan donörlerinde HBsAg, anti-HCV, anti-HIV, sifiliz seroprevalansı ve macro-ELISA sonuçlarının optik dansite değerleri ile doğrulama testlerinin karşılaştırılması. Türk Mikrobiyol Cem Derg. 2012; 42: 137-41.

17. Türk-Dağı H. Batman Bölge Devlet Hastanesi Transfüzyon Merkezine başvuran kan vericilerinin HBsAg, Anti-HCV ve Anti-HIV sonuçlarının değerlendirilmesi. Klimik Derg. 2011; 24: 173-5. 
18. Abbas AK, Lichtman AH. Basic Immonulogy: Functions and disordersof the immune system. 1st edition. New York, USA: Saunders Elseiver Inc, 2007.

19. Brooks GF, Carroll KC, Butel JS, Morse SA, Mietzner TA. Jawetz, Melnick, \& Adelbergs Medical Microbiology. 26th Edition. USA: The McGraw-Hill Companies, 2013.

20. Dinç B, Karabiber N, Yağcı S, Arca EA, Gürbüz A, Tolunay EA. Türkiye Yüksek İhtisas Eğitim ve Araştırma Hastanesi'nde kan donörlerinin serolojik profili. Türk Hij ve Den Biyol Derg. 2011; 68: 1722.

21. Ağuş N, Yılmaz NÖ, Cengiz A, Şanal E, Sert H. Kan donörlerinde HBsAg, anti-HCV, anti-HIV seroprevalans1. ANKEM Derg. 2008; 22: 7-9.

22. Kaya S, Alanoğlu G, Polat M, Sipahi T. Süleyman Demirel Üniversitesi Tıp Fakültesi Kan Merkezi'nin 2000-2007 yılları tarama test sonuçları. SDÜ Tıp Fak Derg. 2009; 16: 13-5.

23. Özcan Deveci, Alicem Tekin, Seda Sibel Günbay, Dilek Kılıç, Sedat Kaygusuz, Canan Ağalar, Türkan Toka Özer. Kan bağışçılarında HBsAg, anti-HCV, anti-HIV ve VDRL testi sonuçlarının değerlendirilmesi. Klinik ve Deneysel Araştırmalar Dergisi. 2011; 2(4): 416-9.

24. Altındiş M, Kalaycı R, Koçoğlu F, Aktepe OC. Afyonkarahisar ili kan donörlerinde beş y1l süre ile enfeksiyon etkenlerinin araştırılması. Kocatepe Tıp Derg. 2007; 8: 1-4.

25. Ulutürk R. Kan donörlerinde yapılan rutin tarama testlerinin 11 yıllık değerlendirilmesi. Türk Mikrobiyol Cem Derg. 2010; 40: 41-7. 